\title{
Predicting the behavioral intention of pregnant women's choice of delivery method based on the theory of planned behavior: A cross-sectional study
}

\author{
Bahareh Soheili ${ }^{1}$, Amin Mirzaei ${ }^{1}$, Kourosh Sayemiri ${ }^{2,3}$, Zeinab Ghazanfari ${ }^{1,2 *}$
}

1. Department of Health Education, Faculty of Health, Ilam University of Medical Sciences, Ilam, Iran

2. Research Center for Prevention of Psychosocial Injuries, Ilam University of Medical Sciences, Ilam, Iran

3. Department of Social Medicine, Faculty of Medicine, Ilam University of Medical Sciences, Ilam, Iran

*Corresponding author:Tel: +98 8432235735 Fax: +98 8432235735

Address: Department of Public Health, Faculty of Health, Ilam University of Medical Sciences, Ilam, Iran

E-mail: ghazanfari-z@medilam.ac.ir

Received; 2015/12/28 revised; 2016/05/22 accepted; 2016/07/10

\section{Abstract}

Introduction: Cesarean, as a major abdominal surgery, if done without a medical indication, may impose numerous complications on the mothers and the babies and increase frequency of cesarean deliveries in subsequent pregnancies. This study aimed to predict the behavioral tendencies of pregnant women in selecting their delivery approaches, based on the theory of planned behavior (TPB).

Materials and methods: This cross-sectional study was performed on 100 pregnant women referred to healthcare centers of Kermanshah city (western Iran). A researcher-made questionnaire was applied, based on TPB constructs including attitudes, perceived behavioral controls, subjective norms, and behavioral tendencies. To analyze the data, Pearson correlation, Spearman, s regression, and ANOVA were used via the SPSS statistical software, version 20.

Results: The average age of pregnant woman was $23.7 \pm 3.93$ years old. The results demonstrated a significant correlation between the subjective norms and behavioral tendencies $(\mathrm{r}=0.335, \mathrm{P}=0.001)$. A significant relationship was seen between the perceived behavioral controls and tendencies $(\mathrm{r}=0.277, \mathrm{P}=0.004)$. A significant relationship was found between the perceived behavioral control and the attitude $(\mathrm{r}=0.293, \mathrm{P}=0.002)$. The results of the regression results demonstrated that the subjective norms and perceived behavioral controls can significantly predict 14.1 percent of changes in the variable of tendencie.

Conclusion: The findings indicate the strength of the variable of subjective norms as the most effective factor in predicting the delivery approach; therefore, systematic and planned training seems necessary, not only for the pregnant women, but also the individuals affecting this group. Thus, to reduce caesarean sections, physicians, as an effective factor, need to be urged to boost natural childbirth.

Keywords: Natural childbirth, Cesarean section, Theory of planned behavior, Pregnant women

\section{Introduction}

Cesarean is a major abdominal surgery, which leads to lower risks of death and diseases among pregnant women, if only applied on appropriate cases. The World Health Organization (WHO) has announced the Cesarean deliveries among nulliparous women at 10 to 15 percent, while the results of many studies show high figures of Cesarean without medical indications in many countries. Performing unnecessary Cesarean increases the rate of repeated cesareans in subsequent deliveries which, in turn, is likely to result 
in causing problems in internal organs (1, 2).

The common factors affecting the Cesarean rate are often individual and social ones such as legal medical considerations, fear of patients' complaints, the mothers' ages, level of education, the family affluence, fear of natural childbirth, and the belief that Cesarean is associated with less pain for mothers (3). Compared with natural childbirth, Cesarean has more complications for mothers and the fetuses such as postpartum depression, fever, cesarean scar infection, bleeding, thromboembolism, abdominal infection, anesthesia complications, and fertility decline. Moreover, Cesarean leads to higher mortality and financial costs $(4,5)$.

In 2010, the WHO announced that 46 percent of the 137 studied countries had Cesarean rates higher than 20 percent, while it reached to 50 percent in Brazil and China later on (2).

In 2010, 25 percent of child birth in UK and 40 to 50 percent in the USA underwent cesarean operations (6). The Ministry of Health and Medical Education in Iran has reported the Cesarean rate by 36 percent in 2002 and 42.3 in 2006, respectively (7).

In recent years, the elective Cesarean rate increased with more complications for mothers and fetuses compared with natural deliveries as well as higher costs imposed on families and the community $(8,9)$. Thus, recent research in the world aims to examine the factors causing such an increase in Cesarean rate and to find a proper way to reduce it through appropriate educational interventions (1). Since several studies have shown that the Theory of Planned Behavior (TPB) is effective in examining and determining the risk factors affecting the occurrence or the absence of a specific behavior (10-12), in our study, the theory has been used as a framework for research. Based on the psychological theory, this model is originated from the theory of rational action and the most important predictor of an individual's behavior is his/her behavioral tendency. The components of this theory are as follows:

Behavior: It is an individual's clear and visible action that is done consciously or unconsciously.

Behavioral tendency: It is an individual's decision to perform or not to perform a specific behavior which is the immediate determinant of behavior.

Attitude: It means, to some extent, that the given behavior is desirable to an individual, and that behavioral beliefs and evaluations of the results can lead to its formation.

Subjective norms: It is the amount of perceived social pressure experienced by an individual to perform or not to perform a behavior and, in fact, it refers to the important roles of others in personal life and the extent of their effects on an individual's life.

Perceived behavioral control: It is the extent to which a person is able to do or not to do a particular behavior and how to control his/her behavior. It is formed by the controlled beliefs and perceived abilities.

The three components of attitude, subjective norms, and perceived behavioral control affect behavioral tendency; meanwhile, the behavioral tendency is the best predictor of the behavior (13-15).

In a study by Rahmati Najarkolaei et al; the variables of subjective norms and perceived behavioral control predicted the selection of the delivery type (16). In their study, KaramiMatin et al; showed that attitudes, perceived behavioral control, and subjective norms were the strongest factors to predict the tendencies to have Cesarean section (6). A study by Shahraki Sanaviet et al. categorized the four main reasons for selecting Cesarean as psychological causes, low perceived behavioral control, improper subjective norms, and unfavorable attitudes to natural delivery (17). 
Therefore, this study was planned using the TPB to predict pregnant women's behavioral tendencies to choose the approach of delivery. Obviously, the data obtained from our investigation will be an evident reason for intervention to influence their behaviors as well as to reduce the Cesarean delivery rate.

\section{Materials and methods}

This cross-sectional study was conducted on pregnant women referred to health care centers in the city of Kermanshah, Iran, during 2014-2015. Taking into consideration the alpha error of $5 \%$ and beta of $10 \%, 100$ nulliparous pregnant women were selected as samples out of the 8 health care centers through convenient sampling. The inclusion criteria consisted of the first pregnancy, gestational age of 28 to 36 weeks, and the expecting mothers' age of less than 35 years old. The data collection instrument was a twosection questionnaire containing 50 items. The first section with 9 items was related to demographic questions; the second included 8 items on the attitudes (behavioral beliefs: 8 items, evaluations of the results: 8 items), 5 items regarding subjective norms (normative beliefs: 5 items, motivation to comply: 5 items), 6 items associated with perceived behavioral control (control beliefs: 6 items, perceived power: 6 items), and 3 items for the behavioral tendency.

The questions in the second part were classified using the 5-choice Likert scale from strongly disagreed to strongly agree. The content validity was confirmed via the panel of experts (specialists), i.e. the questionnaire was prepared through the available literature and modified according to teachers' and experts' comments. Then, its reliability was measured by Cronbach's alpha as 0.82 for the attitude, 0.77 for subjective norms and 0.70 and 0.84 for perceived behavioral control and behavioral intention, respectively. The data were gathered by interviews with the participants. The fill-out time of each questionnaire was about ten minutes. Questions were asked personally by the researcher. Satisfying the samples and ensuring them of the data confidentiality were of the ethical considerations in this study. The data were analyzed using the SPSS software and descriptive statistics, Spearman correlation and regression, and one-way ANOVA.

\section{Results}

The mean age of pregnant women referred to the health centers was $23.7 \pm 3.93$. In Table 1, the demographic data related to the participants is illustrated in terms of frequency and percentage. As it is shown, $96 \%$ of the participants are housewives. In terms of their husband's occupations, $47 \%$ are self-employed. In terms of education, $51 \%$ of participants and $49 \%$ of their spouses were high school graduates. 66 percent earned less than 10 million Rials (about 330 dollars) and $83 \%$ had intended pregnancy.

In Table 2 the mean and standard deviation of the components of TPB have been shown.

Table 3 illustrates the correlation coefficients among the variables. Based on these results, the relationship was proved significant between the subjective norms and behavioral tendency, $(\mathrm{r}=0.335)$, the perceived behavioral control and behavioral tendency, $(\mathrm{r}=0.277)$, and also sig between the behavioral control and attitudes ( $\mathrm{r}=0.293)$.

In Table 4, multivariate linear regression analysis was used to predict the behavioral tendency, the variables of perceived behavioral control, subjective norms, and attitudes. As it is shown, subjective norms and perceived behavioral control can significantly predict behavioral tendency, which predict $14.1 \%$ of the changes in behavioral tendency considering adjusted regression coefficient. 
Table 1. Relative and absolute frequency of the participants' social-economical situation.

\begin{tabular}{llc}
\hline Variables & & $\mathrm{N}(\%)$ \\
\hline Occupation & Housewife & $96(96 \%)$ \\
& Private sector & $4(4 \%)$ \\
Husband's occupation & Worker & $26(26 \%)$ \\
& Employee & $23(23 \%)$ \\
& Jobless & $4(4 \%)$ \\
Education & Self-employed & $47(47 \%)$ \\
& Primary school & $12(12 \%)$ \\
& Junior high school & $26(26 \%)$ \\
Husband's education & High school & $51(51 \%)$ \\
& University & $11(11 \%)$ \\
& Primary school & $8(8 \%)$ \\
Income & Junior high school & $21(21 \%)$ \\
& High school & $49(49 \%)$ \\
& University & $22(22 \%)$ \\
Intended pregnancy & Less than 1 million & $66(66 \%)$ \\
& between 1 and 2 million & $30(30 \%)$ \\
\hline
\end{tabular}

Table 2. The mean and standard deviation of TPB constructs.

\begin{tabular}{lcc}
\hline Constructs & Range of attainable score & Mean \pm SD \\
\hline Attitude & $8-200$ & $104.67 \pm 31.4$ \\
Subjective norms & $5-125$ & $65.77 \pm 22.85$ \\
Perceived behavioral control & $6-150$ & $80.31 \pm 14.3$ \\
Behavioral intention & $3-15$ & $10.53 \pm 2.5$ \\
\hline
\end{tabular}

Table 3. Pearson correlation coefficients between the constructs of the TPB.

\begin{tabular}{|c|c|c|c|c|c|c|c|c|c|c|}
\hline & 1 & 2 & 3 & 4 & 5 & 6 & 7 & 8 & 9 & 10 \\
\hline Behavioral beliefs & 1 & & & & & & & & & \\
\hline Outcome evaluation & 0.16 & 1 & & & & & & & & \\
\hline Normative beliefs & $* * 0.30$ & -0.08 & 1 & & & & & & & \\
\hline Motivation to comply & 0.01 & -0.10 & $* * 0.5$ & 1 & & & & & & \\
\hline Control beliefs & $* * 0.29$ & -0.14 & 0.18 & 0.16 & 1 & & & & & \\
\hline Perceived ability & -0.01 & $* *-0.38$ & -0.12 & -0.12 & -0.12 & 1 & & & & \\
\hline Attitude & $* * 0.95$ & $* * 0.44$ & $* 0.25$ & -0.05 & $* 0.21$ & 0.12 & 1 & & & \\
\hline Subjective norms & 0.18 & -0.08 & $* * 0.84$ & $* * 0.87$ & $* 0.20$ & -0.15 & 0.12 & 1 & & \\
\hline Perceived behavioral control & $* * 0.30$ & 0.06 & 0.14 & 0.06 & $* * 0.85$ & $* * 0.4$ & $* * 0.29$ & 0.12 & 1 & \\
\hline Behavioral intention & $* 0.23$ & -0.1 & $* * 0.38$ & $* 0.24$ & $* 0.28$ & 0.05 & 0.17 & $* * 0.36$ & $* * 0.29$ & 1 \\
\hline
\end{tabular}

**Significant at the level of 0.01

*Significant at the level of 0.05

Table 4. Predictors of pregnant women's behavioral intention to choose the delivery method.

\begin{tabular}{|c|c|c|c|c|c|}
\hline Independent predictors & $\mathrm{B}$ & $\begin{array}{c}\text { Lower confidence } \\
\text { interval }\end{array}$ & $\begin{array}{l}\text { Upper confidence } \\
\text { interval }\end{array}$ & $\mathrm{P}$ value & $\begin{array}{l}\text { Regression } \\
\text { model indices }\end{array}$ \\
\hline Constant & 3.23 & 2.146 & 8.177 & 0.001 & $\mathrm{R}=0.375$ \\
\hline $\begin{array}{l}\text { Attitude towards natural } \\
\text { childbirth }\end{array}$ & 0.003 & -0.013 & 0.019 & 0.594 & $\begin{array}{l}\mathrm{R}^{2}=0.141 \\
\mathrm{sig}=0.002\end{array}$ \\
\hline Subjective norms & 0.022 & 0.009 & 0.052 & 0.001 & \\
\hline Perceived behavioral control & 0.027 & 0.004 & 0.073 & 0.018 & \\
\hline
\end{tabular}




\section{Discussion}

Based on the TPB, this study was conducted to predict the behavioral tendencies to choose the approach of delivery. In this study, no statistically significant relationship was observed between the demographic characteristics and the behavioral intentions to choose the delivery method. There was a weak correlation between the age and behavioral tendency $(\mathrm{r}=-0.072)$. As well, there was no significant difference between education (illiterate, primary school, junior high school, high school, and university graduate) and intention (F3, $96=0.604, \mathrm{P}$ $=0.61)$. Also, There was no significant difference between income (less than 1 million, 1 to 2 million, 2 to 3 million, more than 3 million) and intention $(F 3,96=$ $0.392, \mathrm{P}=0.75$ ).

These results were consistent with the results of studies conducted by Rahmati Najarkolaei et al. (2014) (16); while, in a study by Rafati et al.,2014, it was revealed that variables such as prenatal care, history of abortion, economic status, place of birth, history of previous Cesarean deliveries in the family have a significant relationship with determination of the Cesarean labor (18). Gallagher et al. also demonstrated that factors such as age, education level, and economic status had an impact on the choice of delivery type and the intention to do more Cesarean augmented with the increase in age, education, and income (3). Therefore, lack of relationship between the demographic and behavioral intentions in this study is expressed in the way that more than half of the households (66 percent) have incomes below one million Tomans (about 330 dollars), which is a low income. Another factor was associated with education, i.e. $89 \%$ of women were high school graduates or below high school level and only $11 \%$ held an academic degree. All the pregnant women participating in the study were nulliparous pregnant women without obstetric complications or history of abortion. These participants also had no pleasant or unpleasant experiences of previous deliveries affecting their choice of the delivery method. Moreover, the samples were all living in one city and had relatively similar social and cultural levels. In this study, the relationship between attitudes and behavioral intentions did not prove significant, but the relationship between attitudes and perceived behavioral control was positively significant. In the study by Shahraki Sanavi et al. (9), pregnant women's attitudes proved effective on the choice of the delivery approach and women with a negative attitude to vaginal delivery were more likely to have Cesarean. Furthermore, in an interventional study, Besharati et al. (19) demonstrated that women had a negative attitude to natural childbirth before training. However, through the intervention based on the TPB, the scores of attitudes and other components significantly increased that eventually had an effect on the behavioral tendency to choose the delivery method.

Sharifirad et al. (20), in their investigation, revealed that training pregnant women's husbands could increase awareness and bring about positive attitudes among pregnant women, a fact that eventually reduces the cesarean sections.

In another study, Salehian et al. (21) demonstrated that $97 \%$ of pregnant women had positive attitudes toward natural childbirth and there was only $3 \%$ of negative attitudes. At the same time, it was observed that the pregnant mothers' awareness of the benefits of natural childbirth and the complications of Cesarean was scant. Although, 63 percent of women in this study expressed priority to natural childbirth, 68 percent of deliveries were done by Cesarean because of physicians' diagnosis in more than half of the cases. Lack of a significant relationship between attitudes and behavioral tendencies in this study might 
be due to pregnant mothers 'attitudes and doctors' attitudes which played a role in pushing the patients to choose the Cesarean approaches of delivery. Nevertheless, they could give the patients knowledge and information they needed to reduce their fear of natural childbirth. In our study, mothers' knowledge level was not measured and their attitude score was 104.67 out of 200. It is suggested that improving mothers' awareness would invert their attitudes to natural childbirth.

Also, in this study, the relationship between perceived behavioral control and intention was significant so as the results are consistent with the study conducted by Rahmati Najar Kolaei et al. (16). Furthermore, Sanavi et al. (9) demonstrated that women with an intention to have Cesarean had no desirable behavioral control and felt that they were not able to undergo normal childbirth. Therefore, it was implied that this intervention variable for reducing the Cesarean could be used as an important variable, namely nulliparous women's self-confidence to do natural delivery should be upgraded through psychological intervention.

In this study, a significant relationship between subjective norms and behavioral intentions was observed which confirmed the results obtained in the studies by Rahmati Najar Kolaei et al. (16), and Sanavi et al. (9). Our investigation also showed that the subjective norm was the most influential factor predicting the delivery method which was in line with the results of the study by Rahmati Najar Kolaei et al. (16), in which half of the participants considered the physicians as the determining factors in choosing the delivery approach. According to Sanavi et

\section{References}

1. Anjali K, Emily W, John K. Web based education and attitude to delivery by Caesarean section in nulliparous women. J Obstet Gynaecol Can. 2014;36(9):768-75. al. (9) pregnant women considered the highest incentives to obedience associated with the selection of the delivery method by their physicians .

Since many individual and social factors play roles in determination of the delivery approach and the Cesarean statistics in many countries are higher than the standard rate (1), it is suggested that in the educational program, all the factors affecting the behaviors of pregnant women such as the families and physicians need to be highlighted with the aim of encouraging them to take natural childbirth. This not only raises the pregnant women's awareness of the benefits of natural childbirth, but it also creates and strengthens their positive attitudes and abilities to overcome their fears and negative attitudes. Along with the support and training by gynecologists, the pregnant women would choose the natural delivery as the preferred approach with confidence and necessary abilities. The improvement of natural childbirth conditions including the places of delivery, staff treatments, as well as providing facilities such as an increase in the number of days of maternity leave compared with the Cesarean delivery should be noted to the authorities and policy makers in the area of health.

\section{Acknowledgments}

This article is an adaptation of the research project approved by Ilam University of Medical Sciences. Thereby, we express our gratitudes to the vice-chancellor for research department of Ilam University of Medical Sciences, as well as all those who helped in carrying out our study.

2. Gibbons L, Belizan J, Lauer J, Betran A, Merialdi M, Althabe F. The global numbers and costs of additionally needed and unnecessary Caesarean sections performed per year: overuse 
as a barrier to universal coverage. Geneva: World Health Organization. 2010.

3. Gallagher F, Bell L, Waddell G, Benoit A, Cote N. Requesting cesareans without medical indications: an option being considered by young canadian women. Birth. 2012; 39(1):39-47.

4. Gass CW. It is the right of every anaesthetist to refuse to participate in a maternal-request caesarean section. Int J Obstet Anesth. 2006; 15(1):33-5.

5. Hart D, Norman J, Callander R, Govan A. Gynaecology illustrated. 5th ed. London: Churchill Livingstone. 2000:301-38.

6. Karami-Matin B, Ataee M, Mirzaei Alavijeh M, Mahboubi M, Aghaei A, Mohammadi P. Cognitive factors related to cesarean intention among Iranian pregnant women. J Biol Todays World. 2014;3(11):251-55.

7. Latif RR, Zakeri HM, Merghati Khoei E. Socio-cultural beliefs, values and traditions regarding women's preferred mode of birth in the north of Iran. Int J Commun Bas Nurs Midwifery. 2015;3(3):165-76.

8. Souza JP, Betran AP, Dumont A, de Mucio B, Gibbs Pickens CM, DeneuxTharaux $\mathrm{C}$, et al. A global reference for caesarean section rates (C-Model): a multi country cross-sectional study. Int J Obstetric Gynaecoly. 2016;123(3):427-36.

9. Sanavi FS, Ansari-Moghaddam A, Shovey MF, Rakhshani F. Effective education to decrease elective caesarean section. J Pak Med Assoc. 2014;64(5):500-5.

10. Perry AR, Langley C. Even with the best of intentions: paternal involvement and the theory of planned behavior. Fam Proc. 2013;52(2):17992.

11. Sivell S, Edwards A, Elwyn G, Manstead A. Understanding surgery choices for breast cancer: how might the Theory of Planned Behaviour and the common sense model contribute to decision support interventions? Health Expect. 2011;14(Suppl1):6-19.

12. Tolma EL, Reininger BM, Evans A, Ureda J. Examining the theory of planned behavior and the construct of self-efficacy to predict mammography intention. Health Educ Behav. 2006;33(2):233-51.

13. Ajzen I. Perceived behavioral control, self-efficacy, locus of control, and the Theory of Planned Behavior. J Appl Soc Psychol. 2002;32(4):665-83.

14. Sharma M, Romas J. Theoretical foundations of health education and health promotion. 2nd ed. United States of America. Jones and Bartlet publishers. 2008.

15. Conner M, Armitage C. Extending the theory of planned behavior: a review and avenues for further research. $\mathbf{J}$ Appl Soc Psychol. 1998;28(15):142964.

16. Rahmati Najar Kolaei F, Eshraghi T, Dopeykar N, Zamani O, Mehdizadeh P. [Determinants of delivery type selection by using Theory of Planned Behaviors (TPB). J Urmia Nurs Midwifery. 2014;12(4):305-13]. (Persian)

17. Sanavi FS, Rakhshani F, AnsariMoghaddam A, Edalatian M. Reasons for elective cesarean section amongst pregnant women; A qualitative study. J Reprod Infertil. 2012;13(4):237-40.

18. Rafati S, MadanI A, Mashayekhi F, Rafati F, Pilevarzadeh M. [Related factors to choose cesarean section among Jiroft pregnant women]. J Prevent Med. 2014; 1(1):23-30. (Persian)

19. Besharati F, Hazavehei S, Moeini B, Moghimbeigi A. [Effect of educational interventions based on Theory of Planned Behavior (TPB) in selecting delivery mode among pregnant women referred to Rasht health centers]. J Zanjan Uni Med Sci. 2011;19 (77):94106. (Persian) 
20. Sharifirad G, Rezaeian M, Soltani R, Javaheri S, Mazaheri MA. A survey on the effects of husbands' education of pregnant women on knowledge, attitude, and reducing elective cesarean section. J Educ Health Promot. 2013; 2:50.
21. Salehian T, Delaram M, Safdari F, Jazayeri F. [Knowledge and attitudes of pregnant women about mode of delivery in health centers of Shahrekord]. J Toloo-e-behdasht. 2007;6(2):1-10. (Persian) 